\title{
EVALUASI TARGET DAN RENCANA KERJA KEGIATAN KADER MASYARAKAT DI DESA CIAPUS, KECAMATAN CIOMAS, KABUPATEN BOGOR
}

\author{
${ }^{1}$ Fakultas Psikologi, Universitas Tarumanagara \\ Email:ritamarkus@fpsi.untar.ac.id \\ ${ }^{2}$ Fakultas Psikologi, Universitas Tarumanagara \\ Email: fransiscar@fpsi.untar.ac.id \\ ${ }^{3}$ Fakultas Psikologi, Universitas Tarumanagara \\ Email:ceciliagiwan.untar@gmail.com
}

Rita Markus Idulfilastri ${ }^{1}$, Fransisca Iriani R.D. ${ }^{2}$, dan Cecilia Giwan Meilian $^{3}$

\begin{abstract}
PKM is a collaboration with Ambissi Association partners who have formed 23 cadres of Ciapus village. The activities are Health Services, Children's Reading Gardens, Savings and Loans, Medicinal Plant and Culinary Product. Problem analysis is related to the targets and work plans that have been made in the PKM of 2018-2019 period last semester. PKM problems now with the aim of seeing the realization of targets and work plans that have been made and to strengthen the understanding of cadres' self-evaluation of achievement thinking patterns. Due to the Covid-19 pandemic, activities were carried out by distributing a questionnaire "Am I ready to carry out target-oriented activities". The theoretical basis uses the need of achievement from McCleland combined with the concept of "Achievement Thinking". There are 19 cadres. The target evaluation shows that the Health, Culinary and Medicinal Plants group has succeeded in achieving the target. Evaluation of the work plan shows that although all cadres are actively working, the weakness of the group is increasing. The results of the assessment of the readiness to carry out target orientation activities were nine cadres of the prestigious type, eight cadres of the affiliative type and two cadres who did not describe their type profile. The internet network is very weak, interaction via the internet / zoom cannot be carried out. This activity uses Rp7,500,000 which are mostly used to increase development capital in five Cadre activities. Outcomes and achievements in the form of the article in the Journal and Copyright of Questionnaire.
\end{abstract}

Keywords: village cadres, evaluation of work targets, evaluation of work plans, achievement thinking patterns

\begin{abstract}
ABSTRAK
PKM merupakan kerjasama dengan mitra Perkumpulan Ambissi yang selama ini telah membentuk kader desa Ciapus sebanyak 23 orang. Kegiatan yang dilakukan meliputi Pelayanan Kesehatan, Taman Baca Anak, Kegiatan Simpan Pinjam, Kegiatan Tanaman Obat dan Kegiatan Produk Kuliner. Analisis permasalahan dikaitkan dengan target dan rencana kerja yang teah dibuat pada PKM periode 2018-2019 semester genap lalu. Permasalahan PKM sekarang dengan tujuan melihat realisasi target dan rencana kerja yang telah dibuat. Disamping itu untuk menguatkan pemahaman evaluasi diri kader mengenai pola berpikir prestatif. Pada awalnya evaluasi ini akan dilakukan dalam bentuk pelatihan karena kondisi pandemi Covid-19 kegiatan dilakukan dengan menyebarkan kuesioner "Siapkah saya menjalankan kegiatan berorientasi target". Dasar teori menggunakan need of achievement dari McCleland yang digabungkan dengan konsep "Pola Berpikir Prestatif". Jumlah kader aktif sebanyak 19 orang. Evaluasi target memperlihatkan kelompok Pelayanan Kesehatan, Kuliner dan Tanaman Obat telah berhasil mencapai target. Evaluasi rencana kerja memperlihatkan walaupun semua kader aktif bekerja tapi kelemahan kelompok bertambah. Hasil asesmen kesiapan menjalankan kegiatan orientasi target terdapat sembilan kader bertipe prestatif, delapan kader bertipe afiliatif dan dua kader kurang menggambarkan profil tipenya. Mengingat lokasi di desa jaringan internet sangat lemah maka tidak dapat dilakukan interaksi melalui internet/zoom. Kegiatan menggunakan dana sebanyak Rp 7.500.000 yang sebagian besar digunakan untuk menambah modal pengembangan untuk lima kegiatan Kader. Luaran dan capaian dalam bentuk artikel di Jurnal dan Hak Cipta Kuesioner.
\end{abstract}

Kata kunci: kader desa, evaluasi target kerja, evaluasi rencana kerja, pola berpikir prestatif

\section{PENDAHULUAN}

Kelompok kegiatan kader masyarakat desa Ciapus mengarah pada ekonomi produktif. Kegiatan kader masyarakat terdiri dari kegiatan pelayanan kesehatan (dinamakan Teska), kegiatan taman 
baca anak, kegiatan simpan pinjam, kegiatan tanaman obat dan kegiatan kuliner. Kegiatan pelayanan kesehatan atas kerjasama dengan PT Global Mutualplus dan Rumah Sehat Baznas. Anggota Teska terdiri dari kaum dhuafa di RW 04 (Kampung Bojongsari) dan RW 05 (Kampung Ciherang Cutak) dengan jumlah $251 \mathrm{KK}$ atau 786 jiwa. Pelayanan kesehatan dilakukan setiap minggu oleh seorang dokter dan 6 kader desa secara bergantian. Pasien yang datang berobat ratarata lebih dari 30 orang setiap minggu. Paling banyak pasien menderita penyakit hipertensi, diabetes, ISPA, nyeri sendi, sakit kepala. Manfaat TeSKA bagi kader desa adalah para kader mampu mengorganisasi pembagian tugas tim, mampu mengukur tensi, mampu membaca resep, menginventaris barang-barang Teska. Penambahan sarana di Teska meliputi pengeboran sumur pompa (namun tidak berhasil) dan pembangunan kamar mandi. Foto kader dapat dilihat pada Gambar 1.

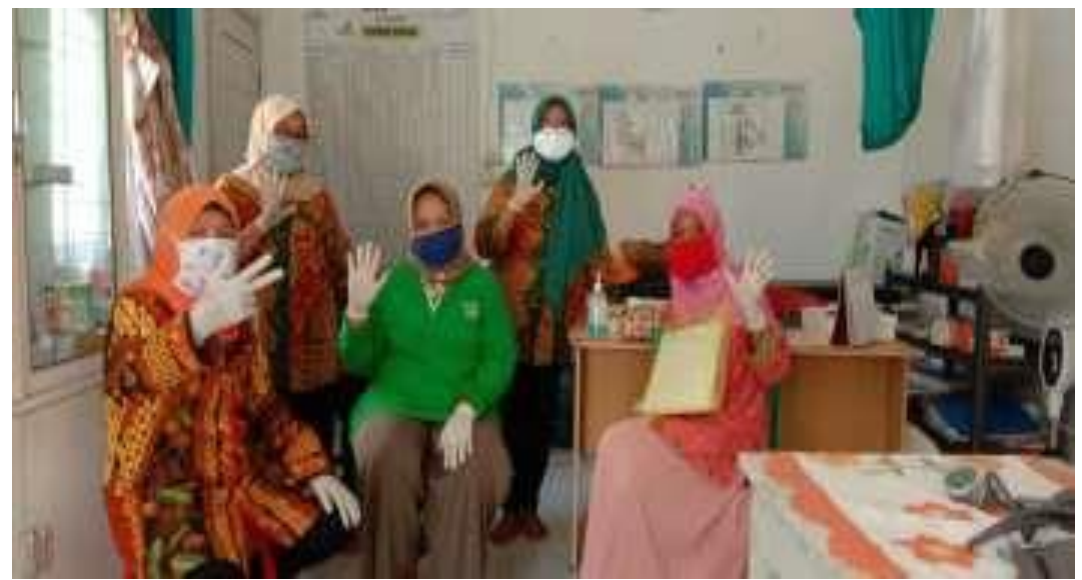

Gambar 1. Foto Kader Pelayanan Kesehatan dengan Protokol Kesehatan

Taman baca anak merupakan kebutuhan desa dibuat di lokasi PAUD dan SD. Saat ini kegiatan Taman Baca berada di PAUD RW 05, PAUD RW 04 dan SD RW 05. Jumlah buku yang tersedia hampir mencapai 4.000 buku. Potensi pembaca terbesar dari anak-anak SD sekitar 270 murid, sedangkan dari PAUD sekitar 30 anak. Pengunjung setiap bulan di PAUD sekitar 100 anak sedangkan di SD bisa mencapai 200 anak. Namun pada kondisi pandemic Covid-19 sekarang, taman baca anak belum dibuka. Karena lokasi taman baca anak di sekolah. Adanya taman baca anak ini memberikan anak-anak membaca dengan topik beragam, mendengarkan dongeng dan pada saat tertentu mengikuti lomba mewarnai. Bagi para kader masyarakat manfaatnya menambah keterampilan mendongeng untuk anak-anak. Taman baca anak dapat dilihat apda Gambar 2.

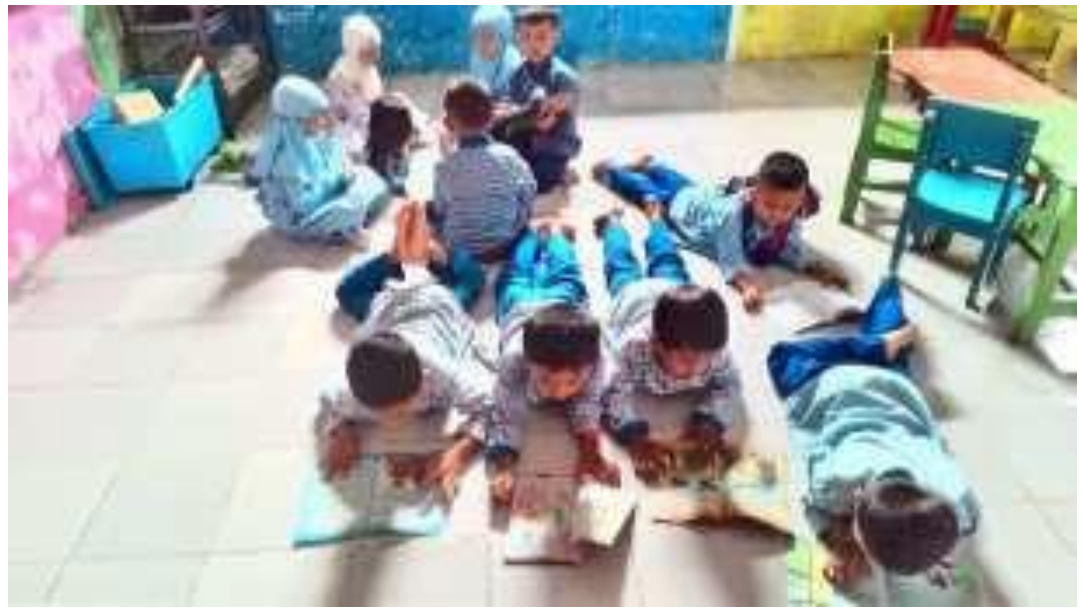

Gambar 2. Foto Anak-anak di Ruang Taman Baca Anak 
Kegiatan simpan pinjam berada di 2 RW yaitu RW 04 dan RW 05. Pinjaman saat ini sekitar Rp 500.000,- - 2.000.000,- digunakan untuk tambahan biaya sekolah anak, biaya pengobatan, modal usaha (sepatu, makanan, kredit barang), pupuk. Jumlah anggota simpan pinjam sekitar 30 anggota, simpanan pokok sebesar Rp 20.000/anggota, simpanan wajib Rp 2.000/minggu dengan jumlah pinjaman telah memcapai Rp 20.000.000. Kegiatan simpan pinjam dapat dilihat pada Gambar 3.

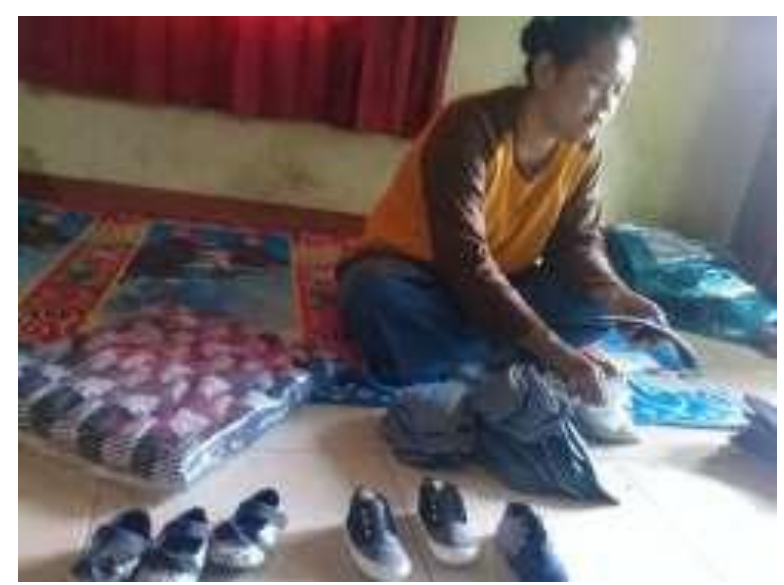

Gambar 3. Foto Menambah Modal Usaha dari Simpan Pinjam

Hasil identifikasi diperoleh produk-produk potensial yang layak jual pada kegiatan kuliner adalah getuk, nasi tumpeng, pepes ikan, wajik, apem, ketimus, kue pisang, dll yang dikelola olah para kader desa. Dalam setiap kegiatan diupayakan sedapat mungkin memanfaatkan kuliner yang dikelola kader desa. Selanjutnya, dapat ditetapkan panganan kering yang layak jual yaitu rengginang, keripik pisang, kue bawang untuk dikembangkan sebagai produk unggulan Desa Ciapus yang dikelola Kader Desa. Produk kegiatan kuliner dapat dilihat pada Gambar 4.

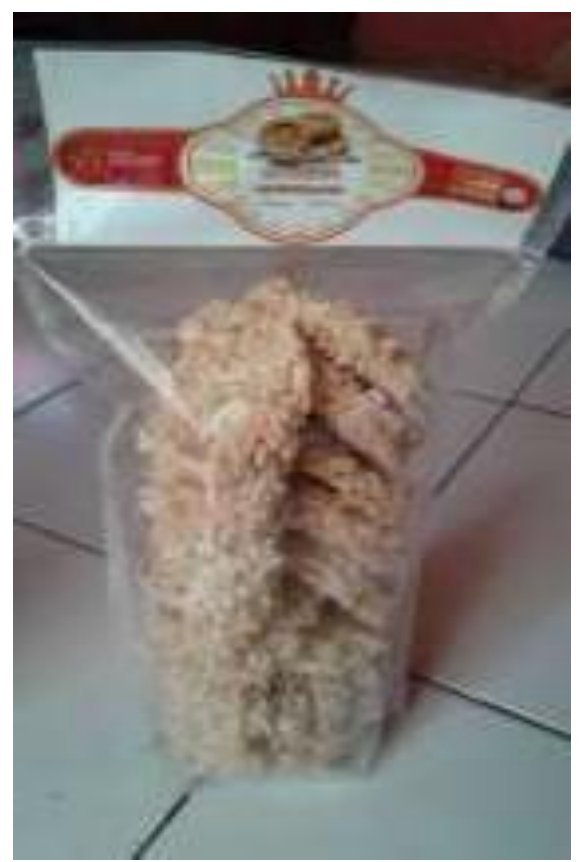

Gambar 4. Foto Produk Kegiatan Kuliner 
Kegiatan tanaman obat dimulai dari perbaikan lingkungan dengan pelatihan di Karinda, Lebakbulus pada April 2014. Kemudian, diproduksi kompos padat limbah dapur. Para kader melakukan sosialisasi, demontrasi, penerapan memproduksi kompos padat limbah dapur kepada warga masyarakat desa. Seorang kader berhasil memproduksi $15 \mathrm{~kg}$ per 4 minggu. Kemudian pada tahun 2017 dilakukan refreshment training oleh salah satu anggota Perkumpulan Ambissi dan berhasil memproduksi $20 \mathrm{~kg}$ kompos padat (dari kotoran hewan) dan 15 liter pupuk cair per 4 minggu. Hasil produksi dapat dijual dengan harga jual pupuk cair per 1,5 liter Rp 35.000,- dan pupuk padat Rp 5.000,- /kg. Kegiatan membersikan lokasi tanaman obat dapat dilihat pada Gambar 5.

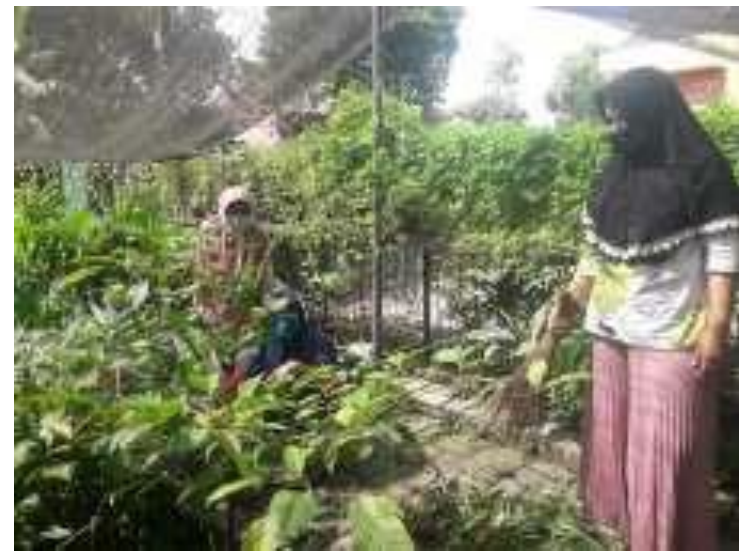

Gambar 5. Foto Membersihkan Lokasi Tanaman Obat

Permasalahan kegiatan Pelayanan Kesehatan adalah Kader masyaraat desa belum semuanya bisa melakukan pengukuran tensi dengan tensimeter dan belum bisa membuat laporan yang rapi. Permasalahan kegiatan Kuliner adalah pemasaran belum bisa secara luas dan keterbatasan modal usaha. Permasalahan kelompok Simpan Pinjam belum bisa membuat laporan sesuai standar dan anggota kadang-kadang belum lancar membayar cicilan. Permasalahan kelompok Tanaman Obat yaitu kader belum paham benar tentang mengurus tanaman obat dan belum bisa membuat laporan kegiatan dengan benar. Kelompok Taman Baca Anak yaitu masih tergantung pada keuangan dari Perkumpulan AMBISSI.

\section{METODE PELAKSANAAN PKM}

Metode pelaksanaan PKM menggunakan pengisian format Evaluasi Target dan Evaluasi Rencana Kerja. Form Evaluasi tersebut terdiri bidang manajemen dan bidang personal (diri sendiri).

Tahapan solusi manajemen disusun format evaluasi dalam bentuk rencana dan realisasi pelaksanaan sesuai dengan target dan rencana kerja yang telah disusun pada setiap kelompok. Format evaluasi dibuat sederhana mungkin agar mudah dan cepat dipahami. Format evaluasi dalam bentuk Modul untuk kelompok Pelayanan Kesehatan, Modul Kelompok Kuliner, Modul Kelompok Simpan Pinjam, Modul Kelompok Tanaman Obat dan Modul Kelompok Taman Baca Anak. Modul tersebut diisi oleh kelompok kegiatan dan Tim PKM melakukan perhitungan, analisis dan kesimpulan. Kegiatan pelaksanaan evaluasi dapat dilihat pada Gambar 6.

Tahapan solusi bidang personal dilakukan dengan asesmen diri. Tujuannya agar para kader paham terhadap kemampuan dirinya dan diharapkan mau melakukan pengembangan dirinya. Adapun tahapan solusinya sebagai berikut: Tim PKM menyusun kuesioner Kesiapan Menjalankan Kegiatan Berorientasi Target berdasarkan Teori Motif Sosial dari McClelland. Kader mengisi Kuesioner. Kader mendapatkan hasil dengan penggolongan apakah sebagai seorang dengan 
keinginan berprestasi atau seorang dengan keinginan afiliasi atau seorang dengan keinginan kekuatan. Kader mendapat penjelasan dari Tim PKM mengenai pengertian keingian tersebut. Kader mendapat penjelasan hubungan antara keinginan dengan Pola Berpikir Prestatif. Kegiatan mengisi kuesioner dapat dilihat pada Gambar 7.

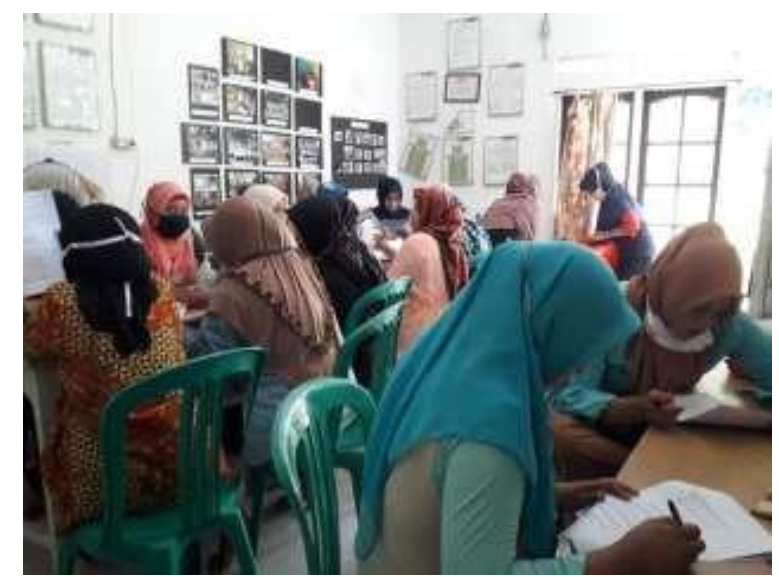

Gambar 6. Foto Evaluasi Target dan Rencana Kerja di Setiap Kelompok

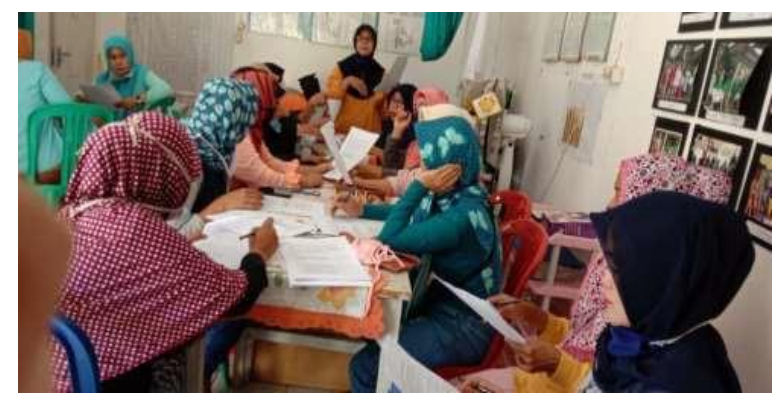

Gambar 7. Foto Mengisi Kuesioner

\section{HASIL DAN PEMBAHASAN}

\subsection{Hasil Evaluasi Target Kerja}

Evaluasi target kerja membandingkan keberhasilan target kerja terhadap rencana kerja yang telah dibuat pada kegiatan PKM di periode 2018-2019 Genap. Ketika menyusun target kerja sekaligus dibuat kriteria yang menjadi ukuran target berhasil. Tabel 1 menggambarkan hasil evaluasi target kerja berdasarkan kelompok kader masyarakat desa, yaitu kelompok kader Pelayanan Kesehatan (Teska), Kuliner, Simpan Pinjam, Tanaman Obat dan Taman Baca Anak.

Tabel 1. Hasil Evaluasi Target Kerja

\begin{tabular}{|c|c|c|c|c|c|}
\hline $\begin{array}{c}\text { Aspek } \\
\text { Evaluasi } \\
\end{array}$ & $\begin{array}{c}\text { Pelayanan } \\
\text { Kesehatan } \\
\end{array}$ & Kuliner & $\begin{array}{ll}\text { Simpan } \\
\text { Pinjam } \\
\end{array}$ & $\begin{array}{c}\text { Tanaman } \\
\text { Obat } \\
\end{array}$ & $\begin{array}{c}\text { Taman Baca } \\
\text { Anak } \\
\end{array}$ \\
\hline Target Kerja & $\begin{array}{l}\text { Semua kader dapat } \\
\text { memahami kegiatan } \\
\text { yang ada di } \\
\text { Pelayanan } \\
\text { Kesehatan. }\end{array}$ & $\begin{array}{l}\text { Tidak tercapai } \\
\text { pemasaran } \\
\text { menjadi lebih } \\
\text { luas. } \\
\text { Tidak ada } \\
\text { produk baru. }\end{array}$ & $\begin{array}{l}\text { Anggota menjadi } \\
\text { kurang lancar } \\
\text { menabung. }\end{array}$ & $\begin{array}{l}\text { Penjualan tanaman } \\
\text { belum banyak. }\end{array}$ & $\begin{array}{l}\text { Tidak tercapai } \\
\text { penambahan buku } \\
\text { dan } \\
\text { mempertahankan } \\
\text { jumlah pengunjung. }\end{array}$ \\
\hline $\begin{array}{l}\text { Ukuran } \\
\text { keberhasilan } \\
\text { target kerja }\end{array}$ & $\begin{array}{l}\text { Belum tercapai } \\
\text { kegiatan ini meluas } \\
\text { ke RW lain }\end{array}$ & $\begin{array}{l}\text { Tercapai } \\
\text { untuk tetap } \\
\text { mengutama- } \\
\text { kan kualitas } \\
\text { kudapan. }\end{array}$ & $\begin{array}{l}\text { Belum banyak } \\
\text { terkumpul modal } \\
\text { untuk simpan } \\
\text { pinjam. }\end{array}$ & $\begin{array}{l}\text { Tercapai dengan } \\
\text { menambah } \\
\text { tanaman obat. }\end{array}$ & $\begin{array}{l}\text { Tidak tercapai } \\
\text { pengunjung } \\
\text { bertambah banyak. }\end{array}$ \\
\hline
\end{tabular}


Evaluasi di kelompok Pelayanan Kesehatan menggambarkan semua kader dapat memahami kegiatan yang harus dilakukan tapi dari sisi ukuran keberhasilan target belum tercapai karena telah ditepatkan kelompok ini bisa mencapai target kalau dapat meluaskan kegiatan ke wilayah RW lainnya. Pada kelompok kuliner tidak tercapai targetnya, baik dari sisi pemasaran maupun produksi. Namun kelompok ini masih dapat mengutamakan kualitas kudapannya. Kelompok Simpan Pinjam baik target kerja dan didukung oleh ukuran keberhasilan tidak tercapai. Terjadi kondisi saat ini anggota kurang lancar menabung sehingga belum banyak modal yang dapat diputar untuk simpan pinjam. Hal yang sama terjadi pada kelompok Taman Baca Anak. Target kerja penambahan buku dan mempertahankan jumlah pengunjung belum tercapai. Sedangkan pada kelompok Tanaman Obat penjualan tanaman belum banyak tapi kader sudah berhasil menambah tanaman obat.

\subsection{Hasil Evaluasi Rencana Kerja}

Aspek evaluasi rencana kerja mencakup keaktifan anggota kelompok melakukan kegiatan, kelebihan dan kekurangan kelompok, keunggulan kelompok, pembagian tugas kelompok, tindakan yang dilakukan jika ada ketidak sesuaian rencana dan pertanyaan pada masa pandemi Covid-19. Tabel 2 menunjukkan hasil evaluasi rencana kerja.

Semua anggota kelompok aktif melakukan kegiatan tapi belum ada pengembangan diri. Hal ini dapat dilihat pada kelebihan kelompok yang masih sama seperti dulu. Sedangkan kekurangan kelompok bertambah terutama pada kelompok pelayanan kesehatan dan simpan pinjam. Pada kelompok kuliner kegiatan menjual kuliner ternyata tidak bertambah dan pada kelompok tanaman obat memperbanyak tanaman untuk dijual juga tidak tercapai.

Pada masa pandemi kegiatan pelayanan kesehatan, simpan pinjam dan tanaman obat tetap berjalan, sedangkan kegiatan kuliner dan taman baca anak tidak ada kegiatan. Kelompok Kuliner berinisitif dalam jangka waktu dekat akan memulai kegiatan kembal.

Tabel 2. Hasil Evaluasi Rencana Kerja

\begin{tabular}{|c|c|c|c|c|c|}
\hline $\begin{array}{c}\text { Aspek } \\
\text { Evaluasi }\end{array}$ & $\begin{array}{l}\text { Pelayanan } \\
\text { Kesehatan }\end{array}$ & Kuliner & $\begin{array}{l}\text { Simpan } \\
\text { Pinjam }\end{array}$ & $\begin{array}{c}\text { Tanaman } \\
\text { Obat }\end{array}$ & $\begin{array}{c}\text { Taman Baca } \\
\text { Anak }\end{array}$ \\
\hline $\begin{array}{l}\text { 1. Nama } \\
\text { anggota aktif }\end{array}$ & $\begin{array}{l}\text { Nunung; Kurniasih; } \\
\text { Cucum; } \\
\text { Ratnasih; } \\
\text { Irmawati }\end{array}$ & $\begin{array}{l}\text { Siti Yunersih; } \\
\text { Anisah }\end{array}$ & $\begin{array}{l}\text { Tati Haryati, } \\
\text { Mamas }\end{array}$ & Wawat, Imas & $\begin{array}{l}\text { Nuyanah, Unasih, } \\
\text { Tati }\end{array}$ \\
\hline $\begin{array}{l}\text { 2. Kelebihan } \\
\text { kelompok }\end{array}$ & Tetap sama. & $\begin{array}{l}\text { Tetap sama } \\
\text { yaitu } \\
\text { pemasaran } \\
\text { belum meluas. }\end{array}$ & Tetap sama. & Tetap sama & Tetap sama \\
\hline $\begin{array}{l}\text { 3. } \\
\text { Kekurangan } \\
\text { kelompok: }\end{array}$ & $\begin{array}{l}\text { Bertambah. Kurang } \\
\text { komunikasi. }\end{array}$ & Tetap sama & $\begin{array}{l}\text { Bertambah. } \\
\text { Kurang dapat } \\
\text { memotivasi } \\
\text { anggota } \\
\text { untuk } \\
\text { menabung. }\end{array}$ & $\begin{array}{l}\text { Tetap sama. } \\
\text { Belum paham } \\
\text { nama dan } \\
\text { hasiat } \\
\text { tanaman. }\end{array}$ & $\begin{array}{l}\text { Tetap sama. } \\
\text { Keterbatasan } \\
\text { buku dan } \\
\text { tergantung } \\
\text { dari } \\
\text { Perkumpulan }\end{array}$ \\
\hline
\end{tabular}



di Desa Ciapus, Kecamatan Ciomas, Kabupaten Bogor

\begin{tabular}{|c|c|c|c|c|c|}
\hline $\begin{array}{l}4 . \\
\text { Keunggulan } \\
\text { kelompok } \\
\text { dibandingka } \\
\text { n kelompok } \\
\text { lain: }\end{array}$ & $\begin{array}{l}\text { Bisa mengunjungi } \\
\text { pasien yang } \\
\text { tidak bisa } \\
\text { datang ke Teska } \\
\text { karena kondisi } \\
\text { pasien. }\end{array}$ & Tetap sama & Tetap sama & Tetap sama & $\begin{array}{l}\text { Belum ada } \\
\text { keunggulan } \\
\text { karena } \\
\text { masih } \\
\text { merintis. }\end{array}$ \\
\hline
\end{tabular}

\begin{tabular}{|c|c|c|c|c|c|}
\hline $\begin{array}{l}\text { 5. Siapa } \\
\text { penanggung } \\
\text { jawab? }\end{array}$ & $\begin{array}{l}\text { Ketua bertanggung } \\
\text { jawab. } \\
\text { Bersama }\end{array}$ & $\begin{array}{l}\text { Ketua dan } \\
\text { anggota } \\
\text { bertanggung } \\
\text { jawab. }\end{array}$ & $\begin{array}{l}\text { Ketua } \\
\text { bertanggung } \\
\text { jawab. }\end{array}$ & $\begin{array}{l}\text { Semua } \\
\text { bertanggung } \\
\text { jawab Wawat, } \\
\text { Imas, Rita, Iis. }\end{array}$ & Semua anggota. \\
\hline $\begin{array}{l}6 . \\
\text { Pembagian } \\
\text { tugas } \\
\text { anggota }\end{array}$ & $\begin{array}{l}\text { Anggota dibagi } \\
\text { menjadi } 4 \text { tim } \\
\text { yang terdiri } 6 \\
\text { orang dan ada } \\
\text { pembagian tugas. }\end{array}$ & $\begin{array}{l}\text { Tugas } \\
\text { dilakukan } \\
\text { bersama. }\end{array}$ & $\begin{array}{l}\text { Pembagian tugas } \\
\text { berdasarkan } \\
\text { ketua, } \\
\text { bendahara, } \\
\text { sekretaris. }\end{array}$ & $\begin{array}{l}\text { Pembagian tugas } \\
\text { sudah dijalankan. }\end{array}$ & $\begin{array}{l}\text { Anggota } \\
\text { bertanggung } \\
\text { jawab di } \\
\text { Ciherang Cutak } \\
\text { dan Bojong Sari. }\end{array}$ \\
\hline $\begin{array}{l}\text { 7. Kegiatan } \\
\text { yang } \\
\text { dilakukan }\end{array}$ & $\begin{array}{l}\text { Kegiatan melayani } \\
\text { masyarakat } \\
\text { kaum duafa } \\
\text { tercapai. }\end{array}$ & $\begin{array}{l}\text { Tidak tercapai } \\
\text { menjual } \\
\text { kuliner }\end{array}$ & $\begin{array}{l}\text { Tercapai kegiatan } \\
\text { memberikan } \\
\text { pinjaman } \\
\text { kepada anggota } \\
\text { untuk biaya }\end{array}$ & $\begin{array}{l}\text { Tidak } \\
\text { tercapai } \\
\text { memperbanyak } \\
\text { tanaman untuk } \\
\text { dijual. } \\
\end{array}$ & $\begin{array}{l}\text { Tercapai kegiatan } \\
\text { mewarnai. }\end{array}$ \\
\hline $\begin{array}{l}\text { 8. Tindakan } \\
\text { yang } \\
\text { dilakukan } \\
\text { karena tidak } \\
\text { sesuai } \\
\text { rencana }\end{array}$ & Tidak ada & $\begin{array}{l}\text { Dilakukan } \\
\text { evaluasi }\end{array}$ & Tidak ada & Tidak ada & Tidak ada \\
\hline $\begin{array}{l}\text { 9. Pada masa } \\
\text { pandemi } \\
\text { Covid-19, } \\
\text { bulan Maret } \\
2020 \text { sampai } \\
\text { Juli } 2020 \text {, } \\
\text { apakah } \\
\text { kegiatan } \\
\text { tetap } \\
\text { berjalan? }\end{array}$ & Tetap berjalan & $\begin{array}{l}\text { Tidak } \\
\text { berjalan. } \\
\text { Secepatnya } \\
\text { ingin memulai } \\
\text { kegiatan } \\
\text { kuliner. }\end{array}$ & $\begin{array}{l}\text { Tetap berjalan, } \\
\text { baru dimulai } \\
\text { bulan Juni } \\
2020 \text {. }\end{array}$ & Tetap berjalan. & Tidak berjalan. \\
\hline
\end{tabular}

\subsection{Kesiapan Menjalankan Kegiatan Berorientasi Prestatif}

Berdasarkan kuesioner Kesiapan Menjalankan Kegiatan Berorientasi Prestatif telah diperoleh tipe profil kader masyarakat desa Ciapus, Ciomas, kabupaten Bogor. Kader masyarakat desa dengan tipe prestatif sebanyak 9 orang dan tipe afiliatif sebanyak 8 orang. Ada 2 orang kader dengan profil yang kurang menggambarkan tipe tertentu. Tidak ada kader dengan tipe berkuasa.

Menurut McCleland (2015) Tipe prestatif adalah orang yang memiliki need of achievement tinggi dengan ciri-ciri: Senang menetapkan sasaran kerja yang menantang atau mengandung unsur 'moderate risk' atau risiko yang diperhitungkan; Selalu merasa apapun yang terjadi maka sebagian besar menjadi tanggung jawabnya - personal responsibility; Dalam bekerja mereka selalu ingin untuk memperoleh atau mencari umpan balik - 'using feedback'; Kegiatan yang dihindari adalah tugas atau tanggung jawab yang terlalu mudah untuk diselesaikan, karena tantangannya rendah; Tugas atau tanggung jawab yang terlalu sukar untuk diselesaikan, karena keberhasilan lebih banyak dipengaruhi oleh faktor keberuntungan.

Tipe berkuasa adalah mereka yang berusaha untuk selalu mempengaruhi orang lain, atau 
membuat orang kagum terhadapnya. Bagi mereka hasil akhir lebih penting dari pada proses. Unsur 'kalah' atau 'menang' merupakan hal yang sangat penting. Mempunyai dorongan kuat untuk dilihat sebagai penyelamat, pembantu, penolong atau pahlawan. Tipe berkuasa tidak selalu harus mempunyai konotasi negatif. Tipe afiliatif dalam bekerja mereka lebih mementingkan suasana antara orang-orang yang bekerja dibandingkan dengan pekerjaannya sendiri. Orang-orang dengan need of Affilaion yang tinggi lebih memperhatikan reaksi atau sikap orang lain terhadapnya. Mereka akan merasa tidak nyaman bila orang bertindak kurang bersahabat. Dalam pemilihan karir, mereka sangat dipengaruhi oleh siapa yang akan menjadi atasan atau siapa yang akan menjadi rekan kerja. Jadi pertimbangan utamanya bukanlah apakah suatu pekerjaan menarik dan menantang, terlepas dengan siapa ia bekerja.

Setelah kader memahami tipikal dirinya, kemudian dilanjutkan dengan pengembangan pola berpikir praktis (McClellend, 2010) yang digambarkan pada Gambar 8.

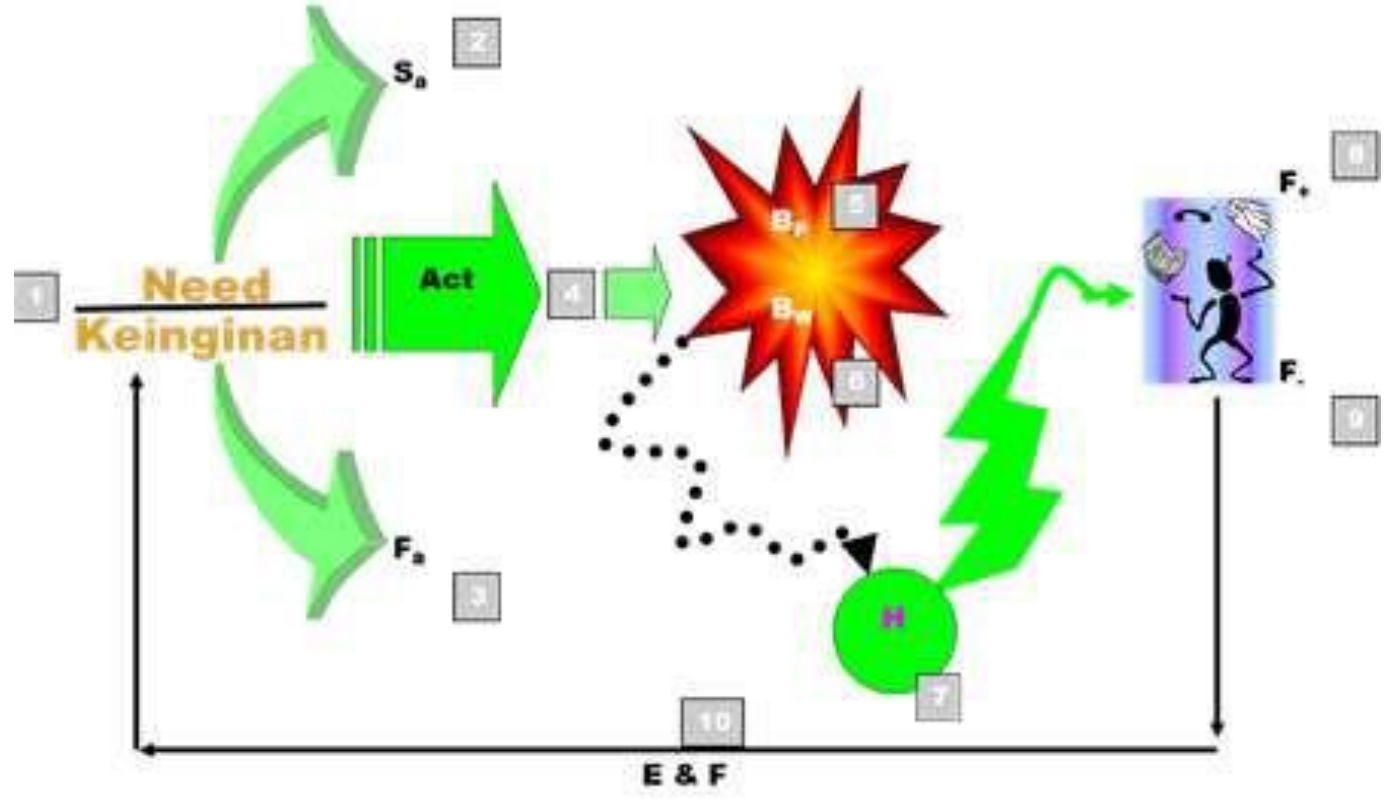

Gambar 8. Pola Berpikir Prestatif

Seorang yang punya keinginan (need) akan mempertimbangkan kemungkinan berhasil (anticipate sailure-Sa) dan kemungkinan gagal (anticpate failure-Fa). Setelah dipertimbangkan dengan matang, kemudian diwujudkan dalam tindakan nyata (act). Tentunya tindakan yang dilakukan tidak selalu berjalan mulus, ada hambatan yang dihadapinya, baik hambatan dari dalam dirinya (block personal-Bp) maupun hambatan dari luar (block world- Bw). Jika mendapat hambatan, tak segan-segan untuk minta bantuan (help-H) sampai akhirnya tercapai keinginannya. Karena keinginan sangat bermakna baginya maka jika berhasil akan merasa senang (feeling psoitif- $F+$ ) dan jika tidak tercapai akan merasa kecewa (feeling negatif- $F$-). Berhasil ataupun gagal selalu dilakukan evaluasi (Evaluation-E) dan bahkan minta umpan balik (Feedback-F) dari orang lain.

Pada akhirnya, diharapkan seorang kader masyarakat desa mempunyai Sikap dan Perilaku Prestatif sebagai berikut Mengambil resiko wajar (moderate risk) dan diperhitungkan, Bertanggung jawab secara pribadi, Memanfaatkan umpan balik, Berusaha mengerjakan sesuatu secara kreatif dan inovatif, merasa dikejar-kejar waktu, menyukai situasi yang serba mungkin (ambiguous), berinisiatif, suka menyelidiki dan mempelajari lingkungan. 


\section{KESIMPULAN DAN SARAN}

Ditinjau dari evaluasi target kerja pada tiap kelompok ternyata hanya kelompok pelayanan kesehatan yang tercapai targetnya. Jika ditinjau berdasarkan ukuran keberhasilan, kelompok yang berhasil mencapai target yaitu kelompok kuliner dan kelompok tanaman obat. Dengan demikian dapat disimpulkan kelompok yang telah berhasil dengan mencapai target kerja adalah kelompok Pelayanan Kesehatan, kelompok Kuliner dan Kelompok Tanaman Obat. Sedangkan kelompok yang belum berhasil mencapai target kerja adalah kelompok Simpan Pinjam dan kelompok Taman Baca Anak.

Semua anggota kelompok aktif melakukan kegiatan tapi belum ada pengembangan diri. Keadaan ini terjadi pada Kelompok Pelayanan Kesehatan dan kelompok simpan pinjam. Hal ini disebabkan oleh tidak adanya pengembangan, sedangkan masalah makin banyak dan beragam. Akibatnya masalah menumpuk dan menjadi kendala di dalam kelompok. Tipe kader sebagian besar pada tipe prestatif dan tipe afiliatif yang relatif seimbang. Tipe prestatif adalah tipe orang yang berorientasi prestatif, maksudnya selalu harus lebih baik dari sebelumnya. Dengan kata lain, kader mempunyai potensi untuk berkembang menjadi pribadi yang berorientasi pada pencapaian target. Namun karena masih ada kader yang mempunyai tipe afiliatif, menyebabkan tipe prestatif kurang menonjol diekspresikan.

Kelompok simpan pinjam, kelompok taman baca anak perlu mendapat perhatian khusus agar tercapai target kerja. Perlu adanya pengembangan diri bagi kader. Hal ini perlu dilaksanakan karena pada dasarnya kader berpotensi bersikap dan berperilaku seorang prestatif. Maksudnya kader mampu mengerjakan tugas-tugas yang berorientasi target. Pengembangan diri kader yang sistematis dan berkelanjutan. Maksudnya agar mendapat pelatihan atau task-force yang dibuat sepanjang 1 tahun dan terus menerus jangan terputus-putus. Tujuannya untuk menggugah/ menyadarkan aspek psikologis.

\section{Ucapan Terima Kasih (Acknowledgement)}

Ucapan terima kasih ditujukkan kepada Perkumpulan Ambissi yang telah menjalin kerjasama sehingga PKM desa Ciapus terlaksana. Terima kasih kepada DPPM UNTAR yang telah memberikan fasilitas dalam bentuk hibah dana tunai.

\section{REFERENSI}

Luthans, F.,Yoessef-Morgan, C.M, Avolio, B.J. (2015). Psychological capital and beyond. USA: Oxford University Press.

McClelland, D. (2015). The Achievement Motive. Martino Fine Books. ISBN-10: 1614278237 ISBN-13: 978-1614278238

McClelland, D. (2010). The Achieving Society. Martino Fine Books. ISBN-10: 1891396390 ISBN13: 978-1891396397

Ryan, R.M., Deci, E.L. (2000). Self-determination theory and the facilitation of intrinsic motivation, social development and well-being. American Psychological Association, 55(1), 68-78.

Sunarsihanto, Pambudi. (2015). Talent Harus Mampu Hadapi VUCA World. Human Capital Journal. Diambil dari: http://humancapitaljournal.com/pambudi-sunarsihantotalent- harus-mampu-hadapi-vuca-world/

Vallerand, R.J., et al (2003). Les passion de $1^{\wedge}$ ame : on obessive and harmonius passion. Journal of Personality and Social Psychology, 85(4), 756-767.

Vallerand, R.J.(2012). The role of passion in sustainable psychological well-being. Psychology of Well Being, a Springer Open Journal, 2:1. Diambil dari : http://www.psywb.com/content/2/1/1. 
Zigarmi, D., Nimon, K.,Houson, D.,Witt, D.,Diehl, J. (2011). A preliminary field test of an employee work passion model. Human Resources Development Quarterly, 12(2), 195- 221

Zhao, Y., St-Louis, A., Vallerand, R.J.(2015). On the validation of the passion scale in chinese.

Psychology of Well Being, A Springer Open Jounal, 5(3). http://www.tribunnews.com/kemenko$\mathrm{pmk} / 2018 / 10 / 26 /$ peran-revolusi-mental-sebagai- lokomotif-perubahan-indonesia?page=2. Jumat, 26 Oktober 2018 14:46 WIB. 